\title{
Uniformidade de Deposição de Gotas de Pulverização em Plantas de Amendoim E Brachiaria plantaginea ${ }^{1}$
}

\author{
Uniformity of Spray Droplet Deposition in Peanut and Brachiaria plantaginea Plants
}

\author{
RODRIGUES-COSTA, A.C.P. ${ }^{2}$, MARTINS, D. ${ }^{3}$ e COSTA, N.V. ${ }^{4}$
}

\begin{abstract}
RESUMO - Objetivou-se neste trabalho avaliar a uniformidade da deposição de gotas de pulverização em plantas de amendoim e de Brachiaria plantaginea localizadas nas linhas e entrelinhas de semeadura da cultura. O experimento de campo foi realizado com a cultura de amendoim, cultivar IAC Tatu-ST. As pulverizações foram feitas com a cultura nos estádios vegetativo (V1) e reprodutivo (R2). Foi utilizado, como marcador das gotas depositadas, o corante Azul Brilhante (FD\&C-1) na concentração de 500 ppm. Os tratamentos foram constituídos por sete pontas de pulverização: XR 110015 VS (150 L ha-1), XR 11002 VS (200 L ha-1), TX-VK 6 (150 L ha-1), TX-VK 8 (200 L ha-1), AI 110015 VS (150 L ha-1), AI11002 VS (200 L ha-1) e TJ60 11002 VS (150 e $\left.200 \mathrm{~L} \mathrm{ha}^{-1}\right)$. Utilizou-se o delineamento experimental em blocos ao acaso, com quatro repetições. Para as análises qualitativas, os dados obtidos foram ajustados à curva de regressão pelo modelo de Gompertz. As pontas XR 11002 VS (200 L ha $\mathrm{L}^{-1}$ ) e TX-VK 6 (150 L ha-1) proporcionaram as maiores uniformidades de distribuição da pulverização nas plantas de amendoim cultivar IAC Tatu ST nos estádios vegetativo (V1) e reprodutivo (R2), respectivamente. A uniformidade de deposição nas plantas de B. plantaginea teve grande variação nos depósitos unitários sobre as plantas localizadas na linha e entrelinha da cultura. Apenas a ponta XR 11002 VS (200 L ha ${ }^{1}$ ) causa falhas de deposição em ambos os estádios de desenvolvimento da B. plantaginea localizada na linha da cultura. Quanto às plantas localizadas na entrelinha, a maior eficiência das pontas de pulverização ocorre no estádio de 3-5 perfilhos.
\end{abstract}

Palavras-chave: ponta de pulverização, tecnologia de aplicação, planta daninha, uniformidade de deposição

\begin{abstract}
The objective of this study was to evaluate the uniformity of spray deposition on peanut and on the weed Brachiaria plantaginea in crop rows and inter-rows. The study was conducted in the field with the peanut cultivar IAC Tatu-ST, and the applications were carried out at the vegetative (V1) and reproductive (R2) stages of the culture. Brilliant Blue (FD\&C-1) was used as tracer in water solution, at $500 \mathrm{ppm}$. The treatments consisted of seven spray nozzles: XR 110015 VS (150 L ha-1), XR 11002 VS (200 L ha-1), TX-VK 6 (150 L ha-1), TX-VK 8 (200 L ha-1), AI $110015 \mathrm{VS}\left(150 \mathrm{~L} \mathrm{ha}^{-1}\right)$, AI1 $1002 \mathrm{VS}$ (200 L ha-1), and TJ60 $11002 \mathrm{VS}\left(150\right.$ and $\left.200 \mathrm{~L} \mathrm{ha}^{-1}\right)$. The experiment was arranged in a randomized block design, with four replications. For the qualitative analysis, the data obtained were adjusted to a regression curve by the Gompertz model. It was concluded that the tips XR 11002 VS (200 L ha-1) and TX-6 VK (150 L ha $\left.{ }^{1}\right)$ showed the highest spray distribution uniformity in the peanut cultivar IAC Tatu ST at the vegetative (V1) and reproductive (R2) stages, respectively. Deposition uniformity in the B. plantaginea plants showed large variations in individual deposits on the plants located on the line and the rows; only the spray nozzle XR 11002 VS (200 L ha-1) showed no deposition failures at both stages of development of B. plantaginea located on the crop line. As for the plants located between the rows, the spray nozzles were most efficient at the 3-5 tiller stage.
\end{abstract}

Keyword: pray nozzle, application technology, weed, deposition uniformity.

1 Recebido para publicação em 10.11.2010 e aprovado em 10.3.2011.

2 Bolsista Pós-Doutorado, UNIOESTE/CCA, Caixa Postal 91, 85960-000 Marechal Cândido Rondon-PR, <andreiacpr@hotmail.com>; ${ }^{3}$ Professor Adjunto, Dep. de Produção Vegetal, FCA-UNESP, Fazenda Lageado, Caixa Postal 237, 18603-970 Botucatu-SP; ${ }^{4}$ Professor Adjunto, UNIOESTE/CCA. 


\section{INTRODUÇÃO}

A cultura do amendoim (Aracahis hypogaea) é cultivada em todo o território brasileiro, geralmente em áreas de renovação de canaviais e de pastagens nas regiões CentroOeste, Sul e Sudeste, onde podem-se obter duas safras por ano (águas e seca). De acordo com as estimativas do IBGE (2010), a produção brasileira do amendoim no ano agrícola 2009/ 10 foi em torno de 266,8 mil toneladas, em 108,2 mil hectares cultivados. No Estado de São Paulo foram produzidos $81,6 \%$ da produção nacional, com o rendimento médio de $2.691 \mathrm{~kg} \mathrm{ha}{ }^{-1}$. Contudo, a produtividade média em várias regiões do País é considerada baixa, em razão de fatores edafoclimáticos, fitotécnicos, incidência de pragas e doenças, bem como da interferência de plantas daninhas.

A interferência de plantas daninhas na cultura do amendoim pode reduzir de 10,5 a $92 \%$ a produtividade de grãos (Kasai et al., 1997; Agostinho et al., 2006). Dessa maneira, a utilização de herbicidas no controle das plantas daninhas destaca-se como a alternativa mais eficiente para as extensas áreas de cultivo. Entretanto, ainda há pouca informação na literatura publicada sobre as técnicas mais adequadas de aplicação dos herbicidas na cultura do amendoim.

Em estudos sobre a eficiência das pulverizações em diferentes culturas, constata-se que podem ocorrer perdas por deriva entre 49 e $88 \%$ do total do produto aplicado (Pergher \& Gubiani, 1995; Pergher et al., 1997; Souza et al., 2007). Dessa forma, para o manejo de plantas daninhas, a ocorrência de perdas dos herbicidas durante a pulverização pode resultar em falhas de controle, seleção de biótipos resistentes e causar contaminações ambientais diretas e indiretas. Nas pesquisas que envolvem tecnologia de aplicação, as avaliações dos depósitos da calda pulverizada são utilizadas como instrumento para desenvolver e melhorar as técnicas de aplicação. Assim, entre os métodos mais representativos, destaca-se a avaliação dos depósitos da calda aplicada em alvos naturais ou artificiais (Farinha et al., 2009; Villalba et al., 2009).

De acordo com Souza et al. (2007), a presença das plantas daninhas próximo às plantas da cultura pode causar irregularidades na deposição das gotas de pulverização e levar à necessidade de se aumentar a dose dos herbicidas, a fim de que elevados niveis de eficiência sejam alcançados. No caso específico de herbicidas aplicados em pós-emergência, a maior deposição no alvo depende de fatores como volume de aplicação, tipo de bico ou ponta de pulverização e ângulo do bico, das estruturas morfoanatômicas foliares e da arquitetura das plantas (Holloway, 1970; Taylor \& Shaw, 1993; Berni et al., 1999).

Pode haver ainda interação significativa entre o volume de pulverização e o tipo de herbicida utilizado (Knoche, 1994). Entretanto, a eficiência do tratamento fitossanitário com a utilização de produtos de ação sistêmica ou de contato não depende somente da quantidade de ingrediente ativo depositado no alvo, mas também da uniformidade de distribuição do produto sobre a superficie do alvo. Portanto, é atribuição do processo de aplicação distribuir homogeneamente o produto no alvo por meio da técnica mais adequada para determinado manejo de controle.

Assim, objetivou-se avaliar a uniformidade da deposição das gotas de pulverização em plantas de amendoim e de Brachiaria plantaginea localizadas nas linhas e entrelinhas da cultura.

\section{MATERIAL E MÉTODOS}

O experimento foi instalado e conduzido em área agrícola da Fazenda Experimental Lageado denominada "Didática", da Faculdade de Ciências Agronômicas - FCA/UNESP, campus de Botucatu/SP, no ano de 2006. As coordenadas geográficas da área são: latitude de $22^{\circ} 07^{\prime} 56^{\prime \prime}$ S e longitude de $74^{\circ} 66^{\prime} 84^{\prime \prime}$ WGr., com altitude média de $762 \mathrm{~m}$, precipitação média anual de $1.517 \mathrm{~mm}$ e temperatura média anual de $20,6{ }^{\circ} \mathrm{C}$.

O solo da área classifica-se como Nitossolo Vermelho Estruturado, de acordo com o Sistema Brasileiro de Classificação de Solos (Embrapa, 1999), com as seguintes características: $\mathrm{pH}\left(\mathrm{CaCl}_{2}\right)=5,7$; matéria orgânica $\left(\mathrm{g} \mathrm{dm}^{-3}\right)=18,2 ; \mathrm{P}\left(\mathrm{mg} \mathrm{dm}^{-3}\right)=38,5 ; \mathrm{H}+\mathrm{Al}, \mathrm{K}, \mathrm{Ca}$, $\mathrm{Mg}, \mathrm{SB}$ e CTC $\left(\mathrm{mmol}_{\mathrm{c}} \mathrm{dm}^{-3}\right)=28,5 ; 3,9 ; 25,0$; 11,$0 ; 39,9$; e 68,4 , respectivamente; e $\mathrm{V} \%=$ 58,0 . O delineamento experimental utilizado 
foi o de blocos ao acaso, com quatro repetições, e as parcelas, constituídas de cinco linhas da cultura de amendoim e com 6 metros de comprimento.

Utilizou-se o cultivar IAC Tatu-ST, pertencente ao tipo Valência, que tem hábito de crescimento ereto e ciclo vegetativo curto, entre 90 e 110 dias. Antes da instalação do experimento, foram realizadas na área experimental duas arações, sendo uma com arado de aiveca e a outra com grade pesada, além de duas operações com grade niveladora. Para a adubação, no momento da semeadura dos cultivares, aplicaram-se $160 \mathrm{~kg} \mathrm{ha}^{-1}$ de fertilizante químico na fórmula 04-14-08. Por um período de 14 dias após a semeadura (DAS), foi utilizada irrigação por aspersão com turno de rega em regime de dias alternados, para aplicação de lâmina d'água de $15 \mathrm{~mm}$.

A cultura foi semeada em 18/1/2006, no espaçamento de $0,5 \mathrm{~m}$ entre linhas e 21 sementes por metro, para obter a densidade de 14 a 15 plantas por metro. Antes da semeadura, as sementes foram tratadas com o fungicida thiran (40 g i.a. $100 \mathrm{~kg}^{-1}$ de semente).

As plantas de $B$. plantaginea, que surgiram espontaneamente na área, permaneceram em convivência com a cultura durante o período experimental. Semanalmente, foram retiradas manualmente as plantas daninhas de outras espécies que surgiram na área de cada parcela experimental, para evitar interferência nos resultados.

No tocante à avaliação da deposição da pulverização, a aplicação da calda foi realizada aos 16 DAS da cultura do amendoim, que corresponde à primeira época, e aos 31 DAS, que corresponde à segunda época. Na primeira e segunda épocas, as plantas de amendoim encontravam-se nos estádios de desenvolvimento vegetativo (V1) e reprodutivo (R2), respectivamente, conforme descrição de Boote (1982). As plantas de B. plantaginea estavam com 1-2 e 3-4 perfilhos e densidade média da população de 16 e 12 plantas $\mathrm{m}^{-2}$, na primeira e segunda épocas de aplicação, respectivamente. Na Tabela 1 estão descritos os tratamentos utilizados no experimento, em cada época de aplicação.

As pulverizações foram realizadas com um pulverizador costal, pressurizado a $\mathrm{CO}_{2}$, equipado com uma barra com quatro pontas de pulverização espaçadas de $0,5 \mathrm{~m}$ entre si. A barra de pulverização foi passada a $0,5 \mathrm{~m}$ acima das plantas de amendoim. Durante a aplicação dos tratamentos, as parcelas foram protegidas com auxílio de placas de lona plástica $(1,5 \times 2,5 \mathrm{~m})$, para evitar possivel deriva para as parcelas vizinhas.

Quanto às avaliações de depósitos nas plantas, as pulverizações foram feitas com um traçador alimentício, o corante Azul Brilhante (FD\&C-1). A preparação da calda foi realizada a partir da diluição em água destilada do corante referido, na proporção de $500 \mathrm{mg} \mathrm{L}^{-1}$.

As condições meteorológicas no período das aplicações variaram entre 28,9 e $33,9{ }^{\circ} \mathrm{C}$ de temperatura e de 33 a $65 \%$ de umidade relativa do ar, e a velocidade média do vento foi de $2,5 \mathrm{~km} \mathrm{~h}^{-1}$.

Tabela 1 - Descrição dos tratamentos utilizados no experimento, em cada época de aplicação. Botucatu-SP, 2006

\begin{tabular}{|l|l|c|c|c|c|}
\hline \multirow{2}{*}{ Ponta* } & \multirow{2}{*}{ Descrição } & Volume de aplicação & Vazão da ponta & Pressão & Velocidade \\
\cline { 3 - 6 } & & $\left(\mathrm{L} \mathrm{ha}^{-1}\right)$ & $\left(\mathrm{L} \mathrm{min}^{-1}\right)$ & $(\mathrm{KPa})$ & $\left(\mathrm{km} \mathrm{h}^{-1}\right)$ \\
\hline XR Teejet & XR 110015VS & 150 & 0,45 & 175 & 3,6 \\
\hline XR Teejet & XR 11002VS & 200 & 0,60 & 175 & 3,6 \\
\hline Conejet & TX-VK6 & 150 & 0,50 & 500 & 4,0 \\
\hline Conejet & TX-VK8 & 200 & 0,67 & 500 & 4,0 \\
\hline AI Tejet & AI 110015VS & 150 & 0,45 & 200 & 3,6 \\
\hline AI Tejet & AI 11002VS & 200 & 0,60 & 200 & 3,6 \\
\hline Twinjet & TJ60 11002VS & 150 & 0,60 & 175 & 4,8 \\
\hline Twinjet & TJ60 11002VS & 200 & 0,60 & 175 & 3,6 \\
\hline
\end{tabular}

* Spraying Systems Co. (2003). 
Caixas plásticas, tipo gerbox, com dimensões de $11,5 \times 11,5 \times 3,0 \mathrm{~cm}$ foram utilizadas como alvo não biológico e colocadas em cada parcela experimental, com o objetivo de avaliar a quantidade de calda depositada no solo. As caixas foram distribuídas nas quatro linhas centrais da parcela: quatro nas linhas e quatro nas entrelinhas da cultura.

Imediatamente após a aplicação da calda de pulverização, foram coletadas, ao acaso em cada parcela, 25 plantas de amendoim, bem como 25 plantas de $B$. plantaginea localizadas na linha e 25 nas entrelinhas da cultura. As plantas foram coletadas individualmente e rentes ao solo, com o auxílio de pinças e tesouras. Em seguida, as plantas foram acondicionadas em sacos plásticos devidamente etiquetados e levadas ao laboratório, para serem lavadas com água destilada, para recuperação do traçante. As caixas gerbox, provenientes de cada parcela experimental, receberam o mesmo tratamento.

No laboratório, frascos plásticos de cor âmbar, com capacidade de $250 \mathrm{~mL}$, continham 100 e $150 \mathrm{~mL}$ de água destilada para lavagem das plantas, nos estádios de desenvolvimento vegetativo (V1) e reprodutivo (R2), respectivamente. As águas foram colocadas nos sacos plásticos contendo as plantas. Em seguida, os sacos plásticos foram agitados durante 25 segundos, e a solução, recolocada nos frascos. Para determinação da massa seca, as plantas foram colocadas em sacos de papel e posteriormente em uma estufa de ventilação forçada de ar, para secagem por um período de 72 horas, em temperatura de $65 \pm 2{ }^{\circ} \mathrm{C}$, até peso constante.

Os frascos plásticos com as amostras do marcador extraído das plantas coletadas foram devidamente armazenados em uma sala escura. Após, procedeu-se a leituras de absorbância de todas as amostras em espectrofotômetro de feixe duplo, modelo CGB Cintra 20, operando com $10 \mathrm{~mm}$ de caminho ótico e comprimento de onda de $630 \mathrm{~nm}$, para o corante Azul Brilhante (FD\&C-1). Os dados obtidos foram ajustados ao modelo de Gompertz, conforme o método descrito por Souza et al. (2007).

Com o mesmo modelo, foram calculados os valores de moda e os percentis $1,5,10 \mathrm{e}$
50 , conforme a proposta de Negrisoli et al. (2002). Os percentis foram calculados igualando-se a expressão de frequência acumulada a cada um desses valores, para estimar a quantidade que recebe essa proporção de menor deposição da população de plantas avaliadas.

O nível de precisão do modelo de Gompertz foi avaliado por meio dos coeficientes de determinação $\left(R^{2}\right)$ e pelas significâncias dos testes $\mathrm{F}$ e de normalidade. Para realizar essas análises, foi utilizado o programa estatístico Sigmastat 2.0.

\section{RESULTADOS E DISCUSSÃO}

Na Tabela 2 encontram-se os resultados das análise de regressão, os coeficientes de determinação e os valores da moda e dos percentis, para quantificar a deposição da gotas de pulverização em plantas de amendoim nos dois estádios de desenvolvimento.

Utilizando a moda como parâmetro de comparação para os depósitos, observou-se no estádio vegetativo (V1) que, independentemente da ponta utilizada, com exceção do modelo de ponta XR, o volume de $200 \mathrm{~L} \mathrm{ha}^{-1}$ proporcionou os maiores valores de moda, o que determina valores pontuais de depósitos mais frequentes nas plantas de amendoim, quando comparado com o volume de $150 \mathrm{~L} \mathrm{ha}^{-1}$ (Tabela 2). Observou-se que o maior depósito pontual foi obtido com o volume de $200 \mathrm{~L} \mathrm{ha}^{-1}$, com a ponta TX-VK 6, e que este depósito pontual é superior em $168 \%$, em relação à ponta do mesmo modelo TX-VK 8. Contudo, no volume de $150 \mathrm{~L} \mathrm{ha}^{-1}$ ocorreu o menor depósito pontual, seguido pelas pontas XR 11002 VS e TJ60 11002 VS no volume de aplicação de 200 e $150 \mathrm{~L} \mathrm{ha}^{-1}$, respectivamente.

Para os depósitos encontrados no estádio reprodutivo (R2) das plantas de amendoim, cada ponta teve comportamento distinto, o que reforça a ideia de que nem sempre volumes maiores proporcionam maiores depósitos. Os maiores depósitos pontuais ocorreram com a ponta XR $110015 \mathrm{VS}$, que foi superior em $75,5 \%$ ao menor depósito pontual registrado pela ponta TJ60 11002 VS, ambas com volume de aplicação de $150 \mathrm{~L} \mathrm{ha}^{-1}$.

Os valores de depósitos pontuais encontrados nas plantas de amendoim no estádio 
Tabela 2 - Parâmetros do modelo de regressão, moda e percentis dos dados de deposição de gotas de pulverização em dois estádios de desenvolvimento de plantas de amendoim, IAC Tatu ST. Botucatu-SP, 2006

\begin{tabular}{|c|c|c|c|c|c|c|c|c|c|}
\hline \multicolumn{2}{|l|}{ Modelo } & XR $110015 \mathrm{Vs}$ & XR 11002 VS & TXVK 6 & TXVK 8 & AI $110015 \mathrm{VS}$ & \multicolumn{3}{|c|}{\begin{tabular}{l|l} 
AI $11002 \mathrm{VS}$ & TJ60 $11002 \mathrm{VSTJ} 6011002 \mathrm{VS}$
\end{tabular}} \\
\hline \multirow{2}{*}{\multicolumn{2}{|c|}{$\mathrm{y}=\mathrm{e}^{\wedge}\left[\mathrm{a}-\mathrm{e}^{\wedge}\left(-b-\mathrm{c}^{*} \mathrm{x}\right)\right]$}} & \multicolumn{8}{|c|}{ Volume $\left(\mathrm{L} \mathrm{ha}^{-1}\right)$} \\
\hline & & 150 & 200 & 150 & 200 & 150 & 200 & 150 & 200 \\
\hline & & \multicolumn{8}{|c|}{ Estádio Vegetativo (V1) } \\
\hline \multirow{3}{*}{$\begin{array}{l}\text { Estimativa dos } \\
\text { parâmetros }\end{array}$} & $\mathrm{a}$ & 4,6052 & 4,6052 & 4,6052 & 4,6052 & 4,6052 & 4,6052 & 4,6052 & 4,6052 \\
\hline & $\mathrm{b}$ & $-1,8080$ & $-2,0490$ & $-1,3250$ & $-2,4880$ & $-1,6410$ & $-2,6760$ & $-1,0060$ & $-1,7120$ \\
\hline & c & 0,0174 & 0,0242 & 0,0197 & 0,0138 & 0,0132 & 0,0192 & 0,0107 & 0,0143 \\
\hline Erro-padrão & & 1,318 & 2,841 & 1,673 & 2,106 & 2,543 & 1,823 & 1,506 & 2,639 \\
\hline $\mathrm{R}^{2}$ & & $0,998^{* *}$ & $0,991 * *$ & $0,997 * *$ & $0,995^{* *}$ & $0,993^{* *}$ & $0,996^{* *}$ & $0,997^{* *}$ & $0,992^{* *}$ \\
\hline & & \multicolumn{8}{|c|}{$\mu \mathrm{Lg}^{-1}$ de massa seca } \\
\hline \multicolumn{2}{|l|}{ Moda } & 103,91 & 84,67 & 67,26 & 180,29 & 124,32 & 139,38 & 94,02 & 119,72 \\
\hline \multirow{4}{*}{ Percentis (\%) } & 1 & 16,14 & 21,56 & 0,00 & 69,62 & 8,62 & 59,83 & 0,00 & 12,92 \\
\hline & 5 & 40,85 & 39,33 & 11,56 & 100,78 & 41,20 & 82,23 & 0,00 & 42,99 \\
\hline & 10 & 55,98 & 50,21 & 24,92 & 119,85 & 61,13 & 95,94 & 16,07 & 61,40 \\
\hline & 50 & 124,97 & 99,81 & 85,86 & 206,85 & 152,08 & 158,46 & 128,27 & 145,35 \\
\hline & & \multicolumn{8}{|c|}{ Estádio Reprodutivo (R2) } \\
\hline \multirow{3}{*}{$\begin{array}{l}\text { Estimativa dos } \\
\text { parâmetros }\end{array}$} & $\mathrm{a}$ & 4,6052 & 4,6052 & 4,6052 & 4,6052 & 4,6052 & 4,6052 & 4,6052 & 4,6052 \\
\hline & $\mathrm{b}$ & $-2,8680$ & $-2,2400$ & $-2,4310$ & $-2,3430$ & $-1,5890$ & $-1,3000$ & $-2,3620$ & $-2,1430$ \\
\hline & $\mathrm{c}$ & 0,0359 & 0,0288 & 0,0521 & 0,0418 & 0,0249 & 0,0367 & 0,0519 & 0,0409 \\
\hline Erro-padrão & & 2,606 & 2,505 & 2,584 & 1,879 & 2,863 & 1,232 & 2,268 & 2,469 \\
\hline $\mathrm{R}^{2}$ & & $0,992^{* *}$ & $0,992^{* *}$ & $0,992 * *$ & $0,996^{* *}$ & $0,990^{* *}$ & $0,998 * *$ & $0,994 * *$ & $0,993^{* *}$ \\
\hline & & \multicolumn{8}{|c|}{$\mu \mathrm{L} \mathrm{g}^{-1}$ de massa seca } \\
\hline \multicolumn{2}{|l|}{ Moda } & 79,89 & 77,78 & 46,66 & 56,05 & 63,82 & 35,42 & 45,51 & 52,40 \\
\hline \multirow{4}{*}{ Percentis (\%) } & 1 & 37,35 & 24,75 & 17,35 & 19,52 & 2,48 & 0,00 & 16,09 & 15,06 \\
\hline & 5 & 49,33 & 39,68 & 25,60 & 29,80 & 19,75 & 5,53 & 24,37 & 25,57 \\
\hline & 10 & 56,66 & 48,82 & 30,65 & 36,10 & 30,32 & 12,70 & 29,44 & 32,00 \\
\hline & 50 & 90,10 & 90,50 & 53,70 & 64,82 & 78,53 & 45,41 & 52,57 & 61,36 \\
\hline
\end{tabular}

vegetativo (V1), independentemente da ponta e do volume utilizado, foram superiores aos depósitos pontuais registrados no estádio reprodutivo $(\mathrm{R} 2)$.

Segundo Velini (1995), a qualidade da deposição pode ser analisada por meio da frequência acumulada (FA\%), ou seja, os valores medianos para as diferentes porcentagens de população de plantas, e da frequência não acumulada (FNA\%), em que o pico da curva representa a moda, ou seja, os valores de depósitos que aparecem com maior frequência na deposição; a concavidade da curva representa a uniformidade de deposição. Em relação à concavidade, quanto mais plana a curva, maior será a frequência dos valores extremos, o que caracteriza a maior amplitude de depósito na população amostrada, ou seja, maiores diferenças entre os maiores e menores volumes depositados nas plantas. Tofoli (2001) afirma que esse modelo é uma boa ferramenta para utilizar nos estudos de deposições de aplicações de produtos fitossanitários e que a análise a partir da média não é suficiente, sendo necessária a análise da dispersão das deposições.

Na Figura 1 estão apresentadas as curvas de frequência acumulada e não acumulada, para os depósitos de calda de pulverização em plantas de amendoim nos estádios vegetativo (V1) e reprodutivo (R2). A frequência não acumulada ou densidade de probabilidade corresponde à derivada primeira da curva de frequência acumulada. Os picos observados nas curvas representam a curtose, que representa a frequência de valores extremos. Esse fato pode ser entendido da seguinte maneira: quanto mais plano é o pico da curva, maior a quantidade desses valores e, consequentemente, mais desuniformes estes se apresentam (Velini, 1995). 


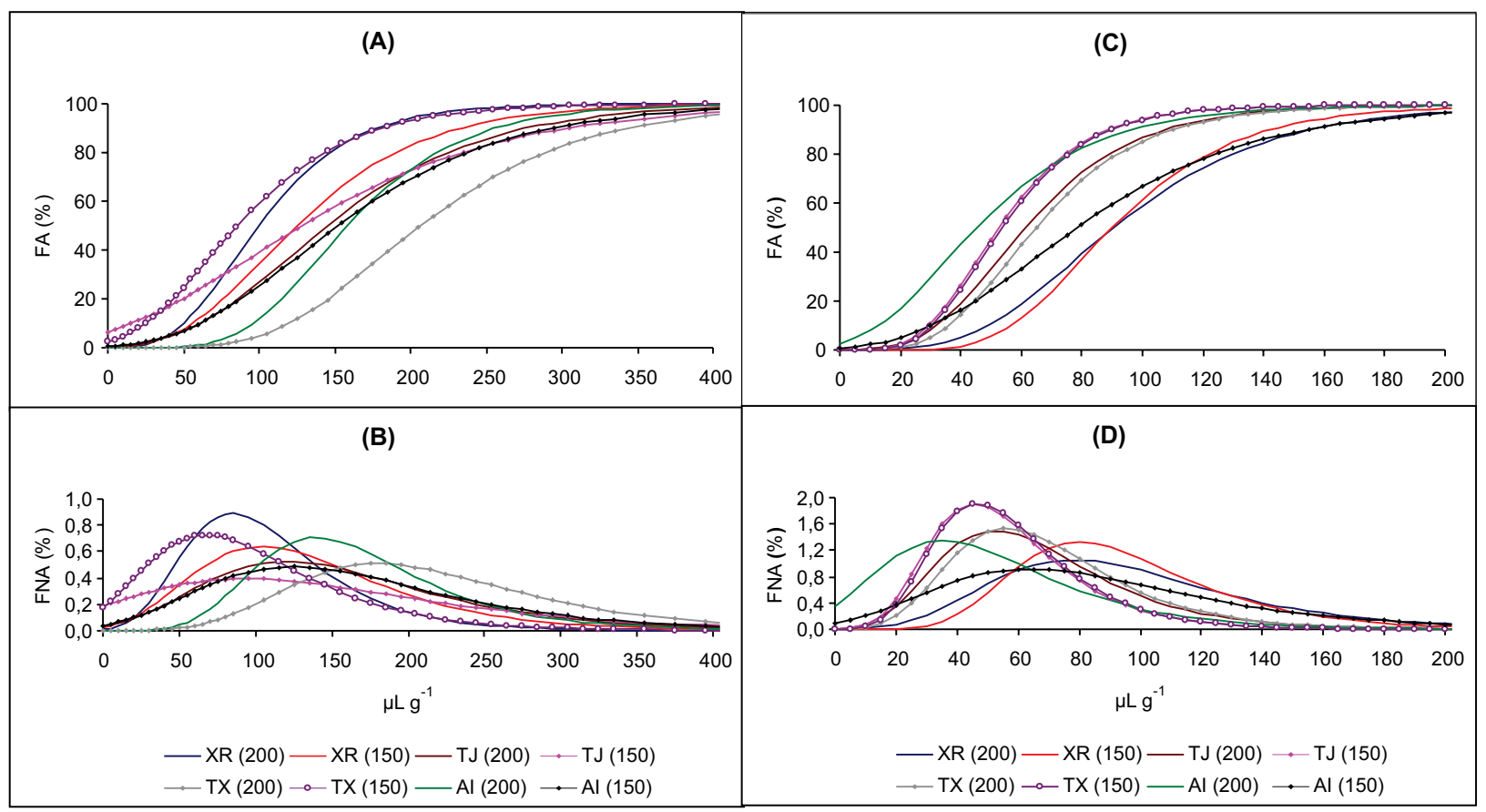

Figura 1 - Frequência acumulada (FA (\%)) e não acumulada (FNA (\%)) em função dos depósitos de gotas de pulverização nos estádios vegetativo (V1) e reprodutivo (R2) de plantas de amendoim, cultivar IAC Tatu ST. Botucatu-SP, 2006. AB: estádio vegetativo (V1); C-D: estádio reprodutivo (R2).

Assim, a uniformidade da deposição da calda de pulverização destaca-se como fator importante no desempenho dos produtos fitossanitários, principalmente quando se consideram produtos de ação de contato, em que é necessária maior área de cobertura do alvo.

Pelo parâmetro "c" do modelo de Gompertz (Tabela 2), os maiores valores correspondem às menores inclinações das curvas e maior uniformidade de deposição da pulverização. Os tratamentos que produziram os depósitos de calda mais uniformes nas plantas de amendoim no estádio vegetativo (V1) foram os correspondentes à ponta XR 11002 VS, seguida pela ponta TX-VK 6, nos volumes de calda de pulverização de 200 e $150 \mathrm{~L} \mathrm{ha}^{-1}$, respectivamente. Esses tratamentos apresentaram os menores valores pontuais de deposição, com valores modais de 84,67 e $67,26 \mu \mathrm{L} \mathrm{g}^{-1}$ de massa seca, respectivamente.

Nesta avaliação, o tratamento que conferiu o menor valor para o parâmetro "c" (menor inclinação da curva), com a menor uniformidade de deposição das gotas pulverizadas, foi o correspondente à ponta TJ 6011002 VS no volume de $150 \mathrm{~L} \mathrm{ha}^{-1}$. Ressalta-se que essa ponta proporcionou o terceiro menor valor de depósitos pontuais entre os tratamentos em teste (Tabela 2).

No estádio reprodutivo (R2), os tratamentos que produziram os depósitos de gotas mais uniformes foram os correspondentes às pontas TX-VK 6 e TJ60 11002 VS, ambas no volume de $150 \mathrm{~L} \mathrm{ha}^{-1}$.

Foi observado que a ponta de pulverização da série TX apresentou melhor desempenho na cobertura das partes da planta de soja, de dificil alcance das gotas, com o volume de $150 \mathrm{~L} \mathrm{ha}^{-1}$. No entanto, as pontas com depósitos de maior variação foram AI 110015 VS, com o volume de aplicação de $150 \mathrm{~L} \mathrm{ha}^{-1}$, e XR 11002 VS, com o volume de $200 \mathrm{~L} \mathrm{ha}^{-1}$.

Ressalta-se que a ponta XR 11002 VS (200 $\mathrm{L} \mathrm{ha}^{-1}$ ) proporcionou menor valor de depósito pontual, $\operatorname{com} 77,78 \mu \mathrm{L}$ de calda $\mathrm{g}^{-1} \mathrm{de}$ massa seca, em relação à ponta XR 110015 VS (150 L ha-1), que apresentou valores de $79,89 \mu \mathrm{L}$ de calda $\mathrm{g}^{-1}$ de massa seca e menor valor de moda (Tabela 2). 
O volume aplicado em uma pulverização deve ser o mais uniforme possivel, sob pena de ser necessário volume adicional para compensar os pontos ou faixas que receberam menor quantidade de calda (Perecin et al., 1998).

Os percentis 1,5 e $10 \%$ da população de plantas em que menos ocorreram depósitos da calda de pulverização podem ser responsáveis pelo insucesso da aplicação de produtos fitossanitários (Negrisoli et al., 2002). Assim, a ponta e/ou volume de aplicação que proporcionar maiores depósitos nas populações de plantas que apresentam maior dificuldade em interceptar as gotas pulverizadas poderão ser considerados os mais eficientes nos processos de aplicação de produtos fitossanitários.

Os depósitos nas plantas de amendoim no estádio vegetativo (V1), em $1 \%$ das plantas em que menos ocorreram depósitos, quando aplicado em volume de $200 \mathrm{~L} \mathrm{ha}^{-1}$, foram maiores em relação ao menor volume $\left(150 \mathrm{~L} \mathrm{ha}^{-1}\right)$; para os demais percentis $(5,10$ e $50 \%)$, ocorreram comportamentos distintos e dependentes da ponta e do volume aplicado. Ressalta-se que houve falhas na aplicação em plantas de amendoim nessa fase de desenvolvimento e que a ponta TX-VK 6 proporcionou falhas em 1\% das plantas amostradas, e a ponta TJ60 11002 VS, falhas em 1 e $5 \%$ da plantas, ambas as pontas com volume de aplicação de $150 \mathrm{~L} \mathrm{ha}^{-1}$. A ponta TJ60 11002 VS, além de proporcionar falhas na aplicação em 1 e $5 \%$ das plantas que menos receberam calda de pulverização, também proporcionou a deposição menos uniforme de todas as pontas em teste.

Um fato interessante observado foi o comportamento do modelo de ponta TX: os depósitos foram muito maiores quando se aumentou o volume de aplicação da calda de pulverização no estádio vegetativo. Esse fato não foi observado nas aplicações realizadas quando as plantas estavam no estádio reprodutivo (R2). Isso se deve, talvez, ao não ajuste do volume para plantas com maior área foliar.

Nas pulverizações realizadas no estádio reprodutivo (R2) das plantas de amendoim, os maiores depósitos na população de plantas que menos receberam calda de aplicação ocorreram com a ponta XR 110015 VS no volume de aplicação de $150 \mathrm{~L} \mathrm{ha}^{-1}$, a qual também proporcionou os maiores depósitos pontuais de calda de pulverização. Notou-se que nesse estádio de desenvolvimento das plantas houve falhas em apenas $1 \%$ das plantas amostradas, as quais foram proporcionadas pela ponta $\mathrm{AI}$ 11002 VS no volume de aplicação de $200 \mathrm{~L} \mathrm{ha}^{-1}$.

Houve falhas da aplicação na população de plantas que não interceptam as gotas durante a pulverização. Dessa forma, o conhecimento das relações entre pontas de pulverização e volumes de aplicação torna-se importante no desenvolvimento dos estudos de tecnologia de aplicação.

Na Tabela 3 estão apresentados os parâmetros estimados da análise de regressão ajustados pelo modelo de Gompertz, a moda e os percentis, para os tratamentos em ambos os estádios de desenvolvimento de $B$. plantaginea localizada na linha de semeadura da cultura do amendoim.

Entre os depósitos pontuais nas plantas de capim-marmelada no estádio de desenvolvimento de 1-2 perfilhos localizadas na linha de semeadura da cultura, com os depósitos mais frequentes, destaca-se a ponta XR 11002 VS no volume de aplicação de $200 \mathrm{~L} \mathrm{ha}^{-1}$, que proporcionou depósitos pontuais de 444,29 $\mu \mathrm{L} \mathrm{g}^{-1}$ de massa seca. $\mathrm{O}$ alto depósito pontual pode ter ocorrido devido a alguma oscilação da barra, ou mesmo por um possivel escorrimento da calda, que explicam os depósitos pontuais tão elevados. Um dado interessante observado foi o da ponta TJ60 11002 no volume de aplicação de $200 \mathrm{~L} \mathrm{ha}^{-1}$, que proporcionou depósitos pontuais de $4,66 \mu \mathrm{L} \mathrm{g}^{-1}$ de massa seca-o menor depósito pontual registrado. Notou-se que essa ponta proporcionou o menor depósito pontual e o segundo menor depósito médio: 119,76 $\mu \mathrm{L} \mathrm{g}^{-1}$ de massa seca.

Nas plantas de $B$. plantaginea que estavam no estádio de desenvolvimento de 3-5 perfilhos não houve depósitos pontuais tão discrepantes como no estádio de 1-2 perfilhos, que foram entre 32,62 e 118,97 $\mu \mathrm{L} \mathrm{g}^{-1}$ de massa seca. A ponta TJ60 11002 VS no volume de aplicação de $200 \mathrm{~L} \mathrm{ha}^{-1}$, ao contrário do estádio de 1-2 perfilhos, foi a que proporcionou o maior depósito pontual registrado nesse estádio de desenvolvimento. A ponta AI 11002 VS, também no volume de $200 \mathrm{~L} \mathrm{ha}^{-1}$, registrou o menor depósito pontual. 
Tabela 3 - Parâmetros do modelo de regressão, moda e percentis dos dados de deposição de gotas de pulverização em dois estádios de desenvolvimento de plantas de B. plantaginea, na linha da cultura do amendoim, IAC Tatu ST. Botucatu-SP, 2006

\begin{tabular}{|c|c|c|c|c|c|c|c|c|c|}
\hline \multicolumn{2}{|l|}{ Modelo } & XR 110015 VS & XR 11002 VS & TXVK 6 & TXVK 8 & AI $110015 \mathrm{VS}$ & \multicolumn{3}{|c|}{ AI 11002 VS TJ60 11002 VSTJ60 11002 V } \\
\hline \multirow{2}{*}{\multicolumn{2}{|c|}{$\mathrm{y}=\mathrm{e}^{\wedge}\left[\mathrm{a}-\mathrm{e}^{\wedge}\left(-\mathrm{b}-\mathrm{c}^{*} \mathrm{x}\right)\right]$}} & \multicolumn{8}{|c|}{ Volume $\left(\mathrm{L} \mathrm{ha}^{-1}\right)$} \\
\hline & & 150 & 200 & 150 & 200 & 150 & 200 & 150 & 200 \\
\hline & & \multicolumn{8}{|c|}{ 1-2 perfilhos } \\
\hline \multirow{3}{*}{$\begin{array}{l}\text { Estimativa dos } \\
\text { parâmetros }\end{array}$} & $\mathrm{a}$ & 4,6052 & 4,6052 & 4,6052 & 4,6052 & 4,6052 & 4,6052 & 4,6052 & 4,6052 \\
\hline & $\mathrm{b}$ & $-0,5190$ & $-1,5550$ & $-1,1000$ & $-0,2360$ & $-0,7310$ & $-0,5230$ & $-0,9290$ & $-0,0904$ \\
\hline & $\mathrm{c}$ & 0,0069 & 0,0035 & 0,0072 & 0,0117 & 0,0085 & 0,0064 & 0,0104 & 0,0194 \\
\hline Erro-padrão & & 5,778 & 4,391 & 2,536 & 10,725 & 3,394 & 5,960 & 4,264 & 13,983 \\
\hline $\mathrm{R}^{2}$ & & $0,966^{* *}$ & $0,977^{* *}$ & $0,993^{* *}$ & $0,865 * *$ & $0,987^{* *}$ & $0,958 * *$ & $0,978^{* *}$ & $0,772 * *$ \\
\hline & & \multicolumn{8}{|c|}{$\mu \mathrm{L} \mathrm{g}^{-1}$ de massa seca } \\
\hline \multicolumn{2}{|l|}{ Moda } & 75,22 & 444,29 & 153,20 & 20,17 & 85,80 & 81,21 & 89,33 & 4,66 \\
\hline \multirow{4}{*}{ Percentis (\%) } & 1 & 0,00 & 7,95 & 0,00 & 0,00 & 0,00 & 0,00 & 0,00 & 0,00 \\
\hline & 5 & 0,00 & 130,80 & 0,39 & 0,00 & 0,00 & 0,00 & 0,00 & 0,00 \\
\hline & 10 & 0,00 & 205,99 & 37,04 & 0,00 & 0,00 & 0,00 & 9,13 & 0,00 \\
\hline & 50 & 128,34 & 549,00 & 204,25 & 51,50 & 128,82 & 138,12 & 124,57 & 23,55 \\
\hline & & \multicolumn{8}{|c|}{ 3-5 perfilhos } \\
\hline \multirow{3}{*}{$\begin{array}{l}\text { Estimativa dos } \\
\text { parâmetros }\end{array}$} & $\mathrm{a}$ & 4,6052 & 4,6052 & 4,6052 & 4,6052 & 4,6052 & 4,6052 & 4,6052 & 4,6052 \\
\hline & $\mathrm{b}$ & $-1,0910$ & $-1,7240$ & $-1,1510$ & $-1,4100$ & $-0,6630$ & $-0,7600$ & $-0,9680$ & $-1,8440$ \\
\hline & $\mathrm{c}$ & 0,0176 & 0,0172 & 0,0183 & 0,0219 & 0,0145 & 0,0233 & 0,0221 & 0,0155 \\
\hline Erro-padrão & & 4,846 & 4,487 & 2,213 & 1,490 & 4,296 & 3,409 & 4,773 & 3,588 \\
\hline $\mathrm{R}^{2}$ & & $0,975^{* *}$ & $0,979^{* *}$ & $0,994 * *$ & $0,997 * *$ & $0,980^{* *}$ & $0,986^{* *}$ & $0,973^{* *}$ & $0,987 * *$ \\
\hline & & \multicolumn{8}{|c|}{$\mu \mathrm{Lg}^{-1}$ de massa seca } \\
\hline \multicolumn{2}{|l|}{ Moda } & 61,99 & 100,23 & 62,90 & 64,38 & 45,72 & 32,62 & 43,80 & 118,97 \\
\hline \multirow{4}{*}{ Percentis (\%) } & 1 & 0,00 & 11,44 & 0,00 & 0,00 & 0,00 & 0,00 & 0,00 & 20,44 \\
\hline & 5 & 0,00 & 36,44 & 2,94 & 14,28 & 0,00 & 0,00 & 0,00 & 48,18 \\
\hline & 10 & 14,60 & 51,74 & 17,32 & 26,30 & 0,00 & 0,00 & 6,06 & 65,16 \\
\hline & 50 & 82,81 & 121,54 & 82,92 & 81,12 & 71,00 & 48,35 & 60,39 & 142,61 \\
\hline
\end{tabular}

Tomazela et al. (2006) avaliaram a deposição de gotas com a ponta XR 8001 EVS em B. plantaginea no estádio de 2 a 3 folhas e verificaram que o consumo de calda de 57,37 , 114,75 e $229,51 \mathrm{~L} \mathrm{ha}^{-1}$ proporcionou $7,21,4,22$ e $3,78 \%$ de depósitos nas plantas, respectivamente. Dessa forma, esses autores concluíram que, à medida que se decresceu o volume de calda de pulverização por hectare, ocorreram acréscimos na porcentagem de depósito nas plantas e, concomitantemente, decréscimos na porcentagem depositada no solo, indicando maior eficácia em atingir o alvo biológico. Resultados contrários foram obtidos no presente estudo para a ponta XR em ambos os estádios de aplicação em $B$. plantaginea.

Na Figura 2 observam-se as curvas de frequências acumulada e não acumulada das plantas de $B$. plantaginea no estádio de desenvolvimento de 1-2 e 3-5 perfilhos. Nos tratamentos com as pontas TJ60 11002 VS,
TX-VK 8, ambas no volume de $200 \mathrm{~L} \mathrm{ha}^{-1}$, e a ponta TJ60 $11002 \mathrm{VS}$, no volume de $150 \mathrm{~L} \mathrm{ha}^{-1}$, ocorreram as menores dispersões dos depósitos de calda e a maior uniformidade dos depósitos. A ponta XR 11002 VS proporcionou maior irregularidade nos depósitos, seguida pela ponta AI 11002 VS, ambas no volume de $200 \mathrm{~L} \mathrm{ha}^{-1}$. De acordo com Souza et al. (2007), essa irregularidade nos depósitos pode levar à necessidade de aumentos na dose aplicada dos herbicidas, para compensar perdas por deriva.

Ressalta-se que a ponta XR 11002 VS no volume de $200 \mathrm{~L} \mathrm{ha}^{-1}$ foi a que proporcionou o maior valor de moda (Tabela 3), ou seja, os maiores valores frequentes de depósitos unitários retidos nas plantas de $B$. plantaginea no estádio de 1-2 perfilhos. Com esta ponta ocorreu a maior dispersão dos depósitos da calda de pulverização entre todos os tratamentos. 
No estádio de desenvolvimento de 3-5 perfilhos, verificou-se que os tratamentos com as pontas AI 11002 VS e TX-VK 8, no maior volume, e a ponta TJ60 11002 VS, no menor volume, foram os que apresentaram a menor dispersão dos depósitos de calda, proporcionando a maior uniformidade dos depósitos (Figura 2). A ponta AI 110015 VS no volume de $150 \mathrm{~L} \mathrm{ha}^{-1}$ proporcionou maior irregularidade nos depósitos, seguida pela ponta TJ60 11002 VS no volume de $200 \mathrm{~L} \mathrm{ha}^{-1}$.

As pontas XR $11002 \mathrm{VS}\left(200 \mathrm{~L} \mathrm{ha}^{-1}\right)$ e TX-VK 6 (150 L ha-1) proporcionaram, no estádio de 1-2 perfilhos de $B$. plantaginea, depósitos de 14,21 e $3,47 \mu \mathrm{L}$ de calda $\mathrm{g}^{-1}$ de massa seca, respectivamente. No estádio de 3-5 perfilhos, os valores apresentados por ambas as pontas foram de 102,71 e $79,78 \mu \mathrm{L}$ de calda $\mathrm{g}^{1}$ de massa seca, respectivamente.

Assim, pode-se verificar que a ponta $X R$ 11002 VS (200 L ha-1) foi superior à TX-VK 6 (150 L ha-1) nos dois estádios de aplicação em B. plantaginea localizada na linha da cultura; contudo, em condições operacionais semelhantes, Maciel et al. (2001) verificaram, em plantas de Brachiaria decumbens (seis folhas) posicionadas sob as plantas de feijão (cinco folhas com foliolos definidos), que as pontas XR 11002 VS (185 $\mathrm{L} \mathrm{ha}^{-1}$ ) e TX-VK 4 (185 $\mathrm{L} \mathrm{ha}^{-1}$ ) proporcionaram depósitos de 45,06 e 71,67 $\mu \mathrm{L}$ de calda $\mathrm{g}^{-1}$ de massa seca, respectivamente. Quando se utilizou o espalhante adesivo Aterbane BR $\left(0,5 \% \mathrm{v} \mathrm{v} \mathrm{v}^{-1}\right)$ na calda de pulverização, as pontas XR e TX proporcionaram depósitos de 31,59 e $122,95 \mu \mathrm{L}$ de calda $\mathrm{g}^{-1}$ de massa seca, respectivamente.

Os autores afirmam ainda que as aplicações com a ponta TX, mais a adição do espalhante adesivo Aterbane $\mathrm{BR}\left(0,5 \% \mathrm{v} \mathrm{v}^{-1}\right)$ na calda de pulverização, pode proporcionar deposição de gotas superior a 289,2 e 172,9\%, em relação à ponta XR com e sem surfatante, respectivamente. Assim, o efeito 'guarda-chuva' promovido pelas plantas de feijão, em aplicações de herbicidas para o controle de plantas daninhas, pode ser minimizado com a redução da tensão superficial da água e com utilização de pontas de pulverização que produzem gotas com diâmetro pequeno.

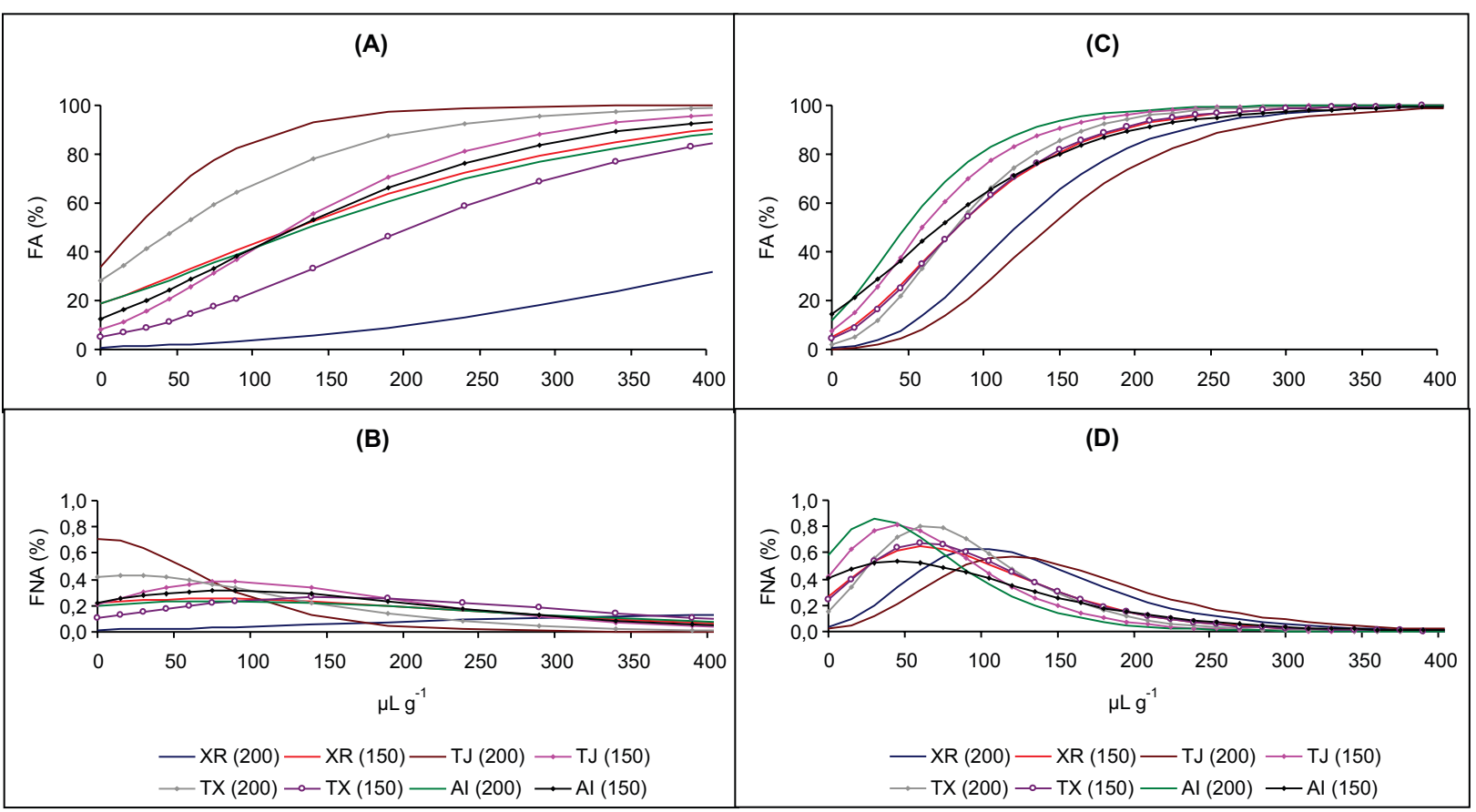

Figura 2 - Frequência acumulada (FA (\%)) e não acumulada (FNA(\%)) em função dos depósitos de gotas de pulverização em plantas de B. plantaginea com 1-2 perfilhos e 3-5 perfilhos, na linha da cultura do amendoim, cultivar IAC Tatu ST. Botucatu-SP, 2006. A-B: 1-2 perfilhos; C-D: 3-5 perfilhos. 
Rodrigues-Costa et al. (2010) avaliaram as pontas XR 110015 VS (150 L ha-1) e XR 11002 VS (200 L ha-1) sem e com a presença do surfatante Silwet (copolímero de poliéster e silicone) a $0,05 \% \mathrm{v} \mathrm{v}^{-1}$ na calda de pulverização na deposição de calda de pulverização em plantas de feijão (estádio V4) convivendo com plantas de $B$. plantaginea (3-4 perfilhos) e verificaram, para as plantas de feijão, que a ponta XR $110015 \mathrm{VS}\left(150 \mathrm{~L} \mathrm{ha}^{-1}\right)$ sem e com a presença do Silwet apresentou valores de moda de 163,04 e $269,48 \mu \mathrm{L}$ de calda $\mathrm{g}^{-1}$ de massa seca, respectivamente, enquanto a ponta XR 11002 VS (200 L ha $\left.{ }^{-1}\right)$ sem e com a presença do Silwet apresentou valores de moda de 229,72 e $298,92 \mu \mathrm{L}$ de calda $\mathrm{g}^{-1}$ de massa seca, respectivamente. O contrário foi observado para plantas de $B$. plantaginea, uma vez que a ponta XR 110015 VS (150 L ha') sem e com a presença do Silwet apresentou valores de moda de 174,01 e $130,65 \mu \mathrm{L}$ de calda $\mathrm{g}^{-1}$ de massa seca, respectivamente; a ponta XR 11002 VS (200 L ha ${ }^{-1}$ ) sem e com a presença do Silwet mostrou valores de moda de 471,15 e 14,69 $\mu \mathrm{L}$ de calda $\mathrm{g}^{-1}$ de massa seca, respectivamente. Esses autores observam ainda que a melhor uniformidade de distribuição das gotas foi obtida para as plantas de B. plantaginea também com o acréscimo do Silwet em ambos os volumes, porém com destaque para o volume de $200 \mathrm{~L} \mathrm{ha}^{-1}$.

Ao se analisar a porcentagem da população de plantas de $B$. plantaginea que recebeu a menor quantidade de depósitos, localizada na linha de semeadura da cultura do amendoim, observaram-se, exceto a ponta XR 11002 VS com o volume de $200 \mathrm{ha}^{-1}$, falhas na deposição. A maioria das pontas proporcionou falhas de $10 \%$ na deposição nas plantas de $B$. plantaginea no estádio de desenvolvimento de 1-2 perfilhos. Esse fato pode ser confundido com uma possivel resistência das plantas daninhas a herbicida. Os maiores depósitos que ocorreram na população de plantas que menos receberam depósitos foram proporcionados pela ponta XR 11002 VS, no volume de 200 ha $^{-1}$; além dos maiores depósitos, foi a única ponta que não proporcionou falhas na deposição. Ressalta-se que essa ponta foi a que proporcionou os maiores depósitos médios encontrados.

Observaram-se falhas de depósitos no estádio de desenvolvimento das plantas de
B. plantaginea com 3-5 perfilhos, porém com menor intensidade que em plantas mais jovens (1-2 perfilhos). Destacam-se as pontas XR 11002 VS e TJ60 11002 VS, ambas no volume de $200 \mathrm{ha}^{-1}$, que proporcionaram os maiores depósitos na população de plantas que receberam menos depósitos e não proporcionaram falhas na deposição das plantas daninhas.

Na Tabela 4 estão apresentados os parâmetros estimados da análise de regressão ajustados pelo modelo de Gompertz, a moda e os percentis, para os tratamentos em ambos os estádios de desenvolvimento da $B$. plantaginea localizada nas entrelinhas de semeadura da cultura do amendoim.

Para as plantas daninhas localizadas nas entrelinhas de semeadura da cultura no estádio de 1-2 perfilhos, a ponta AI 11002 VS no volume de $200 \mathrm{ha}^{-1}$ proporcionou a melhor uniformidade de distribuição das gotas pulverizadas, seguida pela ponta TJ60 11002 VS, no volume de 150 ha $^{-1}$ (Figura 3). Ressaltase que essas pontas foram as que proporcionaram os menores depósitos pontuais e médios, em relação aos demais tratamentos.

Observou-se, no estádio de 3-5 perfilhos, que a ponta TJ60 11002 VS no volume de $150 \mathrm{~L} \mathrm{ha}^{-1}$ proporcionou a menor dispersão dos dados e a melhor uniformidade de distribuição das gotas de pulverização. A ponta XR 110015 VS no volume de $150 \mathrm{~L} \mathrm{ha}^{-1}$ proporcionou a maior dispersão e, consequentemente, menor uniformidade de deposição das gotas. A ponta TJ60 11002 VS seguida pela ponta TX-VK 6, ambas no volume de $150 \mathrm{~L} \mathrm{ha}^{-1}$, proporcionaram as menores dispersões das deposições, o que determinou a melhor uniformidade de distribuição.

A ponta TX-VK 8 no volume de $200 \mathrm{~L} \mathrm{ha}^{-1}$ proporcionou a maior dispersão e o menor valor do parâmetro "c", bem como a concavidade da curva mais plana, o que confere a menor uniformidade entre todos os tratamentos estudados. Resultados contrários foram obtidos por Rodrigues et al. (2010), os quais observaram, em plantas de B. plantaginea (3-4 perfilhos) localizadas na linha de semeadura da cultura do feijão (estádio V4), que a ponta TX-VS 8 no volume de $200 \mathrm{~L} \mathrm{ha}^{-1}$ proporcionou depósitos uniformes com valores de moda de 272,29 $\mu \mathrm{L}$ 
Tabela 4 - Parâmetros do modelo de regressão, moda e percentis dos dados de deposição de gotas de pulverização em dois estádios de desenvolvimento de plantas de B. plantaginea, na entrelinha da cultura do amendoim, IAC Tatu ST. BotucatuSP, 2006

\begin{tabular}{|c|c|c|c|c|c|c|c|c|c|}
\hline \multicolumn{2}{|l|}{ Modelo } & XR $110015 \mathrm{VS}$ & XR 11002 VS & TXVK 6 & TXVK 8 & AI $110015 \mathrm{VS}$ & \multicolumn{3}{|c|}{ 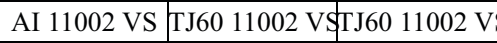 } \\
\hline \multirow{2}{*}{\multicolumn{2}{|c|}{$y=e^{\wedge}\left[a-e^{\wedge}\left(-b-c^{*} x\right)\right]$}} & \multicolumn{8}{|c|}{ Volume $\left(\mathrm{L} \mathrm{ha}^{-1}\right)$} \\
\hline & & 150 & 200 & 150 & 200 & 150 & 200 & 150 & 200 \\
\hline & & \multicolumn{8}{|c|}{ 1-2 perfilhos } \\
\hline \multirow{3}{*}{$\begin{array}{l}\text { Estimativa dos } \\
\text { parâmetros }\end{array}$} & $\mathrm{a}$ & 4,6052 & 4,6052 & 4,6052 & 4,6052 & 4,6052 & 4,6052 & 4,6052 & 4,6052 \\
\hline & $\mathrm{b}$ & $-0,8900$ & $-0,1890$ & $-0,0966$ & $-0,7560$ & $-0,5550$ & $-0,1220$ & $-0,0368$ & $-0,0251$ \\
\hline & $\mathrm{c}$ & 0,0051 & 0,0133 & 0,0278 & 0,0078 & 0,0126 & 0,0421 & 0,0402 & 0,0244 \\
\hline Erro-padrão & & 2,615 & 11,723 & 13,885 & 3,872 & 5,255 & 13,990 & 15,355 & 15,254 \\
\hline $\mathrm{R}^{2}$ & & $0,992^{* *}$ & $0,840^{* *}$ & $0,776^{* *}$ & $0,983 * *$ & $0,969^{* *}$ & $0,780^{* *}$ & $0,727^{* *}$ & $0,730^{* *}$ \\
\hline & & \multicolumn{8}{|c|}{$\mu \mathrm{L} \mathrm{g}^{-1}$ de massa seca } \\
\hline \multicolumn{2}{|l|}{ Moda } & 173,15 & 14,21 & 3,47 & 97,05 & 44,05 & 2,90 & 0,92 & 1,03 \\
\hline \multirow{4}{*}{ Percentis (\%) } & 1 & 0,00 & 0,00 & 0,00 & 0,00 & 0,00 & 0,00 & 0,00 & 0,00 \\
\hline & 5 & 0,00 & 0,00 & 0,00 & 0,00 & 0,00 & 0,00 & 0,00 & 0,00 \\
\hline & 10 & 10,89 & 0,00 & 0,00 & 0,00 & 0,00 & 0,00 & 0,00 & 0,00 \\
\hline & 50 & 244,46 & 41,77 & 16,66 & 144,10 & 73,14 & 11,60 & 10,03 & 16,05 \\
\hline & & \multicolumn{8}{|c|}{ 3-5 perfilhos } \\
\hline \multirow{3}{*}{$\begin{array}{l}\text { Estimativa dos } \\
\text { parâmetros }\end{array}$} & $\mathrm{a}$ & 4,6052 & 4,6052 & 4,6052 & 4,6052 & 4,6052 & 4,6052 & 4,6052 & 4,6052 \\
\hline & $\mathrm{b}$ & $-1,3090$ & $-1,5920$ & $-1,8510$ & $-0,8730$ & $-1,2400$ & $-1,0890$ & $-1,7580$ & $-1,7350$ \\
\hline & $\mathrm{c}$ & 0,0175 & 0,0155 & 0,0232 & 0,0115 & 0,0190 & 0,0151 & 0,0245 & 0,0142 \\
\hline Erro-padrão & & 2,870 & 3,920 & 2,232 & 3,785 & 2,299 & 2,098 & 2,901 & 1,644 \\
\hline $\mathrm{R}^{2}$ & & $0,990^{* *}$ & $0,983 * *$ & $0,994 * *$ & $0,981^{* *}$ & $0,994 * *$ & $0,995^{* *}$ & $0,991 * *$ & $0,997^{* *}$ \\
\hline & & \multicolumn{8}{|c|}{$\mu \mathrm{Lg}^{-1}$ de massa seca } \\
\hline \multicolumn{2}{|l|}{ Moda } & 74,80 & 102,71 & 79,78 & 75,91 & 65,26 & 72,12 & 71,76 & 122,18 \\
\hline \multirow{4}{*}{ Percentis (\%) } & 1 & 0,00 & 4,18 & 13,96 & 0,00 & 0,00 & 0,00 & 9,42 & 14,64 \\
\hline & 5 & 12,10 & 31,92 & 32,49 & 0,00 & 7,52 & 0,00 & 26,97 & 44,92 \\
\hline & 10 & 27,14 & 48,90 & 43,83 & 3,39 & 21,37 & 16,89 & 37,71 & 63,45 \\
\hline & 50 & 95,74 & 126,36 & 95,58 & 107,78 & 84,55 & 96,39 & 86,71 & 147,99 \\
\hline
\end{tabular}

de calda $\mathrm{g}^{-1}$ de massa seca, destacando-se em relação às pontas XR $110015 \mathrm{VS}, \mathrm{XR} 11002 \mathrm{VS}$, TJ60 11002 VS e TX-VS 6 nos volumes de pulverização de 150 e $200 \mathrm{~L} \mathrm{ha}^{-1}$. Quanto às plantas de $B$. plantaginea localizadas na entrelinha, destacou-se a ponta TJ60 11002 VS (200 L ha-1), com deposição de 368,60 $\mu \mathrm{L}$ de calda $g{ }^{1}$ de massa seca.

Em avaliações da deposição de gotas de pulverização nas plantas de $B$. plantaginea (2-8 folhas) na cultura da soja (2-4 trifólios), a utilização da ponta de jato plano $\left(110^{\circ}-\mathrm{SF}-01\right)$ no volume de aplicação de $250 \mathrm{~L} \mathrm{ha}^{-1}$ proporcionou depósitos 34,0\% maiores e mais uniformes nas plantas de $B$. plantaginea localizadas na entrelinha, em relação às localizadas nas linhas da cultura (Souza et al., 2007).

Observou-se, para o estádio de 1-2 perfilhos, que todas as pontas apresentaram falhas em até $10 \%$ da população de plantas em que menos receberam calda de pulverização, com exceção da ponta XR 110015 VS no volume de $150 \mathrm{~L} \mathrm{ha}^{-1}$, em que houve falhas em 1 e $5 \%$ das plantas. Esta ponta foi a que proporcionou o maior depósito unitário e médio, em relação às demais. Esses depósitos foram da ordem de 173,15 e 477,24 em $\mu \mathrm{L}$ de calda $\mathrm{g}^{-1}$ de massa seca, respectivamente.

Semelhantemente aos resultados observados nas plantas presentes na linha de semeadura da cultura, nas plantas de B. plantaginea, no estádio de 3-5 perfilhos, ocorreu a menor intensidade de falhas de deposição, registrada para as pontas XR 110015 VS e AI 110015 VS no volume de $150 \mathrm{~L} \mathrm{ha}^{-1}$, que apresentaram falhas em $1 \%$ das plantas e até $5 \%$ para os tratamentos com as pontas TX-VK 8 e AI 11002 VS no volume 


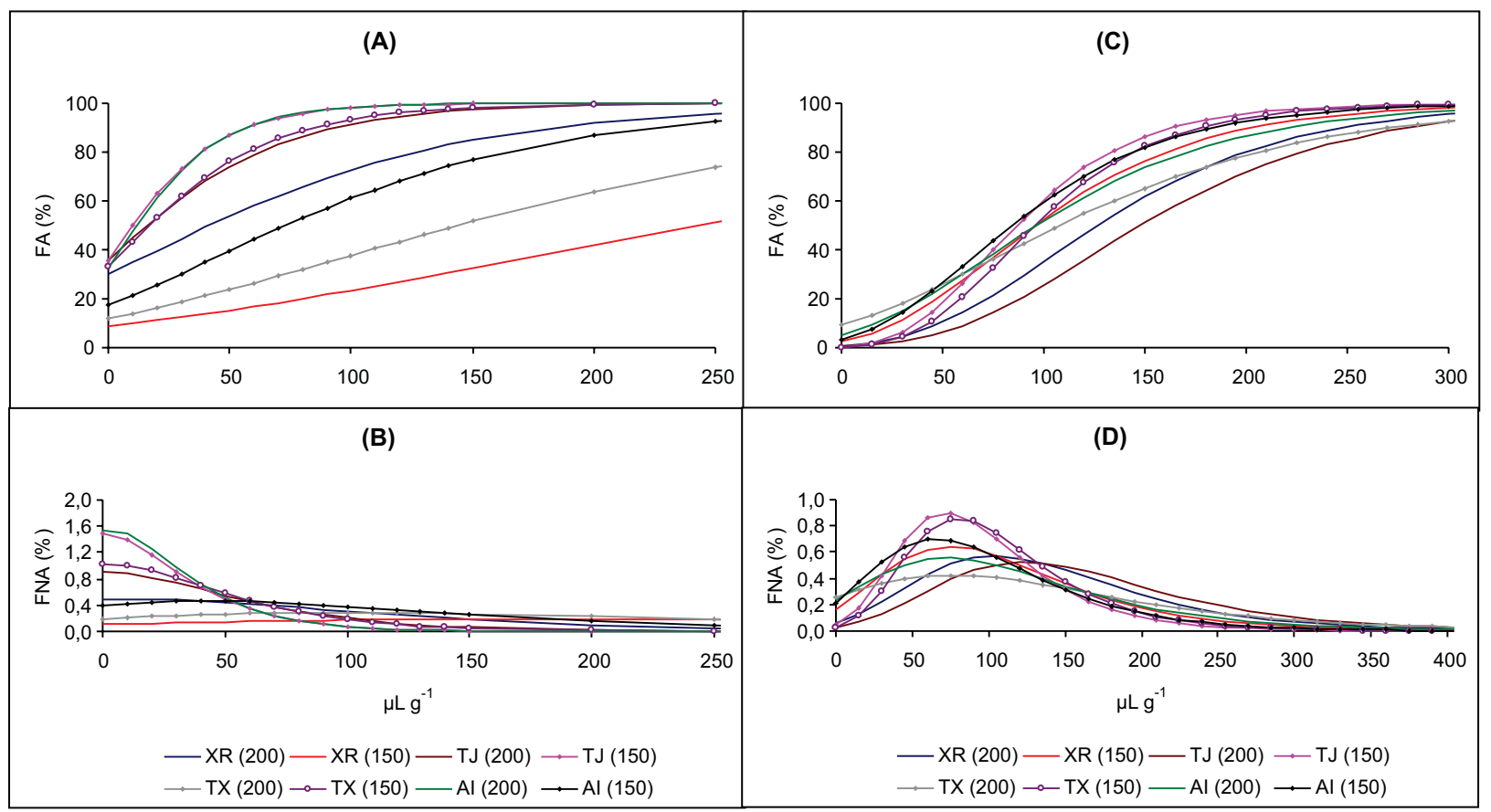

Figura 3 - Frequência acumulada (FA(\%)) e não acumulada (FNA(\%)) em função dos depósitos de gotas de pulverização em plantas de B. plantaginea com 1-2 perfilhos e 3-5 perfilhos, na entrelinha da cultura do amendoim, cultivar IAC Tatu ST. Botucatu-SP, 2006. A-B: 1-2 perfilhos; C-D: 3-5 perfilhos.

de $200 \mathrm{~L} \mathrm{ha}^{-1}$. Isso pode ter ocorrido pelo fato de as plantas no estádio de 1-2 perfilhos apresentarem menor área foliar para a interceptação das gotas, em relação ao estádio de 3-5 perfilhos.

Ressalta-se que, independentemente da ponta utilizada, da posição em que as plantas encontravam-se e do estádio de desenvolvimento delas no momento das aplicações, houve falhas de até $10 \%$ das plantas. A ausência de deposição de gotas de pulverização nas plantas de $B$. plantaginea pode ser explicada pela quantidade de cera na superficie adaxial maior que na abaxial (Mendonça, 2000).

A deposição das gotas de pulverização também pode ser influenciada pelas características morfológicas, como pilosidade, superficie cuticular, forma e rugosidade das folhas (Hess \& Falk, 1990; Wirth et al., 1991; Taylor \& Shaw, 1993).

Independentemente da posição das plantas daninhas em relação à cultura, do volume de aplicação e das pontas de pulverização utilizadas, pode haver falhas da aplicação, considerando a população de plantas que não interceptam as gotas de pulverização durante a aplicação. Dessa forma, o conhecimento das relações entre pontas de pulverização, volumes de aplicação e espécies de plantas daninhas torna-se importante no desenvolvimento dos estudos de tecnologia de aplicação.

Para as condições em que o presente trabalho foi desenvolvido, pode-se concluir que as pontas XR 11002 VS (200 L ha-1) e TX-VK 6 $\left(150 \mathrm{~L} \mathrm{ha}^{-1}\right)$ proporcionaram as maiores uniformidades de distribuição da pulverização em plantas de amendoim cultivar IAC Tatu ST nos estádios vegetativo (V1) e reprodutivo (R2), respectivamente. Os depósitos de gotas nas plantas de $B$. plantaginea mostraram grandes variações nos depósitos unitários sobre as plantas localizadas nas linhas e nas entrelinhas da cultura e não proporcionaram os depósitos mais uniformes. A ponta XR 11002 VS (200 L ha-1) não apresentou falhas de deposição em ambos os estádios de desenvolvimento de $B$. plantaginea localizada nas linhas da cultura, e, nas plantas localizadas nas entrelinhas, as pontas apresentaram maior eficiência no estádio de 3-5 perfilhos. 


\section{LITERATURA CITADA}

AGOSTINHO, F. H. et al. The effect of cultivar on critical periods of weed control in peanuts. Peanut Sci., v. 33, n. 1, p. $29-35,2006$

BERNI, R. F. et al. Avaliação da cobertura de gotas provocada por diferentes bicos de pulverização na cultura do milho e do feijão. Pesq. Agropec. Trop., v. 29, n. 1, p. 49-52, 1999.

BOOTE, K. J. Growth stages of peanut (Arachis hypogaea L.). Peanut Sci., v. 9, n. 1, p. 35-39, 1982

EMPRESA BRASILEIRA DE PESQUISA AGROPECUÁRIA - EMBRAPA. Centro Nacional de Pesquisa de Solos. Sistema brasileiro de classificação de solos. Brasília: Embrapa Produção de Informação; Rio de Janeiro: Embrapa Solos, 1999. 412 p.

FARINHA, J. V.; MARTINS, D.; COSTA, N. V. \& DOMINGOS, V. D. Deposição da calda de pulverização em cultivares de soja no estádio R1. Ci. Rural. v. 39, n. 6, p. $1738-1744,2009$

HESS, F. D.; FALK, R. H. Herbicide deposition on leaf surfaces. Weed Sci., v.38, p.280-288, 1990.

HOLLOWAY, P. J. Surface factors affecting the wetting of leaves. Pestic. Sci., v. 1, n. 1, p. 56-63, 1970.

FUNDAÇÃO INSTITUTO BRASILEIRO DE GEOGRAFIA E ESTATÍSTICA - IBGE. Levantamento sistemático da produção agrícola: pesquisa mensal de previsão e acompanhamento das safras agrícolas no ano civil. Rio de Janeiro, v. 23, n. 7, p.1-80, 2010

KASAI, F. S. et al. Efeitos dos períodos de competição do mato na cultura do amendoim: I safra da seca de 1988.

Bragantia, v. 56, n. 2, p. 323-331, 1997

KNOCHE, M. Effect of droplet size and carrier volume on performance of foliage applied herbicides. Crop Protec. v. 13, n. 3 , p. $163-178,1994$.

MACIEL, C. D. G. et al. Avaliação do depósito e distribuição da calda de pulverização em plantas de feijoeiro e Braquiaria decumbens. Planta Daninha, v. 19, n. 1, p. 103-110, 2001.

MENDONÇA, C. G. Algumas características da superfície foliar de diversas plantas daninhas monocotiledôneas. 2000. 89 f. Dissertação (Mestrado em Agronomia) - Universidade Estadual Paulista "Júlio de Mesquita Filho", Botucatu, 2000.

NEGRISOLI, E. et al. Depósitos unitários de calda de pulverização com e sem surfactante em plantas de Salvinia molesta. Planta Daninha, v. 20, p. 51-56, 2002. Edição especial.

PERECIN, D. et al. Padrões de distribuição obtidos com bicos TF-4, TJ60-11006 e TQ15006 em mesa de prova. Pesq. Agropec. Bras., v. 33, n. 1, p. 175-82, 1998.
PERGHER, G.; GUBIANI, R. The effect of spray application rate on foliar deposition in a hedgerow vineyard J. Agric. Eng. Res., v. 61, n. 3, p. 205-216, 1995

PERGHER, G.; GUBIANI, R.; TONETTO, G. Foliar deposition and pesticide losses from three air-assisted sprayers in a hedgerow vineyard. Crop Protec., v. 16, n. 1, p. 25-33, 1997

RODRIGUES, A. C. P. et al. Variáveis qualitativas da pulverização em feijão, Bidens pilosa e Brachiaria plantaginea. Ci. Agrotecnol., v. 34, n. 3, p. 698-707, 2010.

RODRIGUES-COSTA, A. C. P. et al. Avaliação de pontas de jato plano na deposição da calda de pulverização com diferentes combinações de plantas de feijão, Brachiaria plantaginea e Bidens pilosa. Planta Daninha, v. 28, p. 1159-1171, 2010.(Numero Especial)

SOUZA, R. T.; VELINI, E. D.; PALLADINI, L. A. Aspectos metodológicos para análise de depósitos de pulverizações pela determinação dos depósitos pontuais. Planta Daninha, v. 25 , n. 1, p. $195-202,2007$

SPRAYING SYSTEMS. Teejet spray products: guia do comprador 202-BR/P. Wheaton: Spraying Systems, 2003. $37 \mathrm{p}$.

TAYLOR, W. A.; SHAW, G. B. The effect of drop speed, size and surfactant on the deposition of spray on barley and radish or mustard. Pestic. Sci., v. 14, n. 6, p. 659-665, 1993.

TOFOLI, G. R. Efeito do tamanho do alvo e condições operacionais sobre a uniformidade de deposição de pulverizadores em pré-emergência. 2001. 62 f. Dissertação (Mestrado em Agronomia/Proteção de Plantas) - Faculdade de Ciências Agronômicas, Universidade Estadual Paulista, Botucatu, 2001

TOMAZELA, M. S. et al. Avaliação da deposição da calda de pulverização em função da densidade populacional de Brachiaria plantaginea, do volume e do ângulo de aplicação. Planta Daninha. v. 24, n. 1, p. 183-189, 2006.

VELINI, E. D. Estudos e desenvolvimento de métodos experimentais e amostrais adaptados à matologia. 1995 250 f. Tese (Doutorado em Agronomia/Produção Vegetal) Faculdade de Ciências Agrárias e Veterinárias, Universidade Estadual Paulista, Jaboticabal, 1995.

VILLALBA, J. et al. Depósito del caldo de aspersión de distintos tipos de boquillas en dos cultivares de soya en el estadio V3. Agrociencia, v. 43, n. 5, p. 465-473. 2009.

WIRTH, W.; STORP, S.; JACOBSEN, W. Mechanisms controlling leaf retention of agricultural spray solutions. Pestic. Sci., v. 33, n. 4, p. 411-420, 1991. 